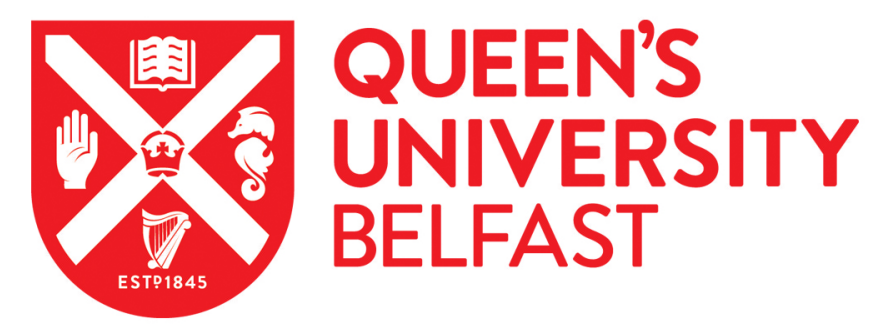

\title{
Industrial wastewater treatment for fertilizer industry—A case study
}

Bhandari, V. M., Sorokhaibam, L. G., \& Ranade, V. V. (2016). Industrial wastewater treatment for fertilizer industry-A case study. Desalination and Water Treatment. https://doi.org/10.1080/19443994.2016.1186399

\author{
Published in: \\ Desalination and Water Treatment
}

Document Version:

Peer reviewed version

Queen's University Belfast - Research Portal:

Link to publication record in Queen's University Belfast Research Portal

\section{Publisher rights}

Copyright 2016 Balaban Desalination Publications. All rights reserved.

This is an Accepted Manuscript of an article published by Taylor \& Francis in Desalination and Water Treatment on 19 May 2016, available online: http://www.tandfonline.com/doi/full/10.1080/19443994.2016.1186399

\section{General rights}

Copyright for the publications made accessible via the Queen's University Belfast Research Portal is retained by the author(s) and / or other copyright owners and it is a condition of accessing these publications that users recognise and abide by the legal requirements associated with these rights.

Take down policy

The Research Portal is Queen's institutional repository that provides access to Queen's research output. Every effort has been made to ensure that content in the Research Portal does not infringe any person's rights, or applicable UK laws. If you discover content in the Research Portal that you believe breaches copyright or violates any law, please contact openaccess@qub.ac.uk. 


\title{
Industrial wastewater treatment for fertilizer industry- A case study
}

\author{
Vinay M. Bhandari ${ }^{\text {a*, Laxmi Gayatri Sorokhaibam }}{ }^{\mathrm{a}, \mathrm{b}}$, Vivek V. Ranade ${ }^{\mathrm{a}}$
}

${ }^{a}$ Chemical Engineering \& Process Development Division, CSIR- National Chemical Laboratory Pune-411 008, India

Tel: 91202590 2171, Fax: 912025893041 , ,email: vm.bhandari@ncl.res.in; laxmigayatri1@gmail.com;

vv.ranade@ncl.res.in

\begin{abstract}
Wastewaters from chemical fertilizer industry mainly contain organics, alcohols, ammonia, nitrates, phosphorous, heavy metals such as cadmium and suspended solids. The nature of effluent streams varies in terms of its constituents and complexity. The present work attempts to fill the void in the literature that mostly reports synthetic wastewater treatment studies; by evaluating effluent treatment solutions and comparison of different methods for real wastewaters from the fertilizer industry. An attempt has been made to devise suitable methodology mainly using a new device in the form of vortex diode for hydrodynamic cavitation and also using adsorption, for several real wastewater streams from different locations in one major fertilizer industry of Maharashtra, India. The strategy involved characterization of wastewaters, studies on the effective removal of Chemical Oxygen Demand(COD) and devising solutions for effective reduction in ammoniacal nitrogen-a more serious issue in the fertilizer industry. The characterization of wastewaters from different streams revealed huge variation in COD from 50 to 140,000 ppm and ammoniacal nitrogen from 6 to $1700 \mathrm{ppm}$. Some effluent streams contained alcohol up to 5 \%. Hydrodynamic cavitation using vortex diode and adsorption with modified carbons were used to treat these streams. Cavitation studies were carried out on a pilot plant and the effect of pressure drop, cavitating device and process intensification were studied. It was observed that the effluent treatment strategy requires careful identification and application of suitable treatment method on the basis of the nature of the effluent. Also, hydrodynamic cavitation, using vortex diode appears to be techno-economically attractive option in treating fertilizer wastewaters giving a very high reduction in COD and ammoniacal nitrogen (up to 85\%), similar to adsorption. The results clearly identify potential of newer methodologies in the treatment of effluents in the fertilizer industry.
\end{abstract}

Keywords: Cavitation, Adsorption, Industry, Effluent, Ammoniacal nitrogen

\section{Introduction}

Industrial wastewater treatment is a complex problem for a variety of highly polluting chemical industries such as fertilizer, distillery, dyes and pigment, textile and specialty chemical manufacturing. Generally, the industrial effluents are characterized in terms of broad parameters such as Chemical Oxygen Demand (COD), Ammoniacal Nitrogen (AN), Total Suspended Solids (TSS), Total Dissolved Solids (TDS) etc. that hardly help in identifying the nature of pollutants in the effluents. The complexity arises mainly from the issues pertaining to the removal of refractory pollutants that are difficult to remove/degrade using conventional methods of treatment, in general, and

\footnotetext{
${ }^{\mathrm{b}}$ Present Address:

Applied Chemistry Department

Visvesvaraya National Institute of Technology Nagpur

South Ambazari Road, Nagpur- 440010

Maharastra, India

Email: laxmigayatri1@gmail.com
} 
biological treatment, in particular. In Indian context, the effluents typically require COD below 250 ppm and AN below 50 ppm for discharge in surface waters, though these norms could differ on the basis of location/country/industry and many a times are even more stricter [1,2]. In recent years, ammoniacal nitrogen in the effluents has received wide attention due to serious threat to environment, requiring further effective pollution control strategies and newer adsorbents [3]. This therefore requires development of highly specific methodologies that help in effectively removing refractory pollutants, either through the use of removal and recovery processes (e.g. adsorption) or through the application of destructive methods such as hydrodynamic cavitation that destroy the pollutants and results in partial/complete mineralization of the pollutant species through advanced oxidation without employing high temperatures/pressures or catalysts[4-6]. For this purpose, industrial wastewater treatment usually employs one or more processes from physical, physico-chemical and biological methods. The traditional methods such as coagulation, adsorption, ion exchange, biological processes, oxidation etc. have their own limitations in the removal of various pollutants and with respect to initial concentrations of pollutants in the effluent streams. These methods have been reviewed and discussed recently for various industrial wastewaters [1]. The application of physical methods is quite straightforward for preliminary treatment- mainly for the removal of suspended solids or $\mathrm{pH}$ adjustment and will not be discussed here. The challenge is in the selection of most appropriate process(es) from physico-chemical methods such as adsorption/ ion exchange/ membranes, newer forms of advanced oxidation processes etc.; biological methods such as aerobic or anaerobic treatment or combination of both, for any specific industry sector/effluent stream. The volume of effluent, nature and concentration of pollutants and total cost of treatment usually dictates the selection.

The fertilizer industry is an important manufacturing sector, especially in India due to its agricultural based economy. The growth of the agricultural sector is significant and is fuelled by variety of fertilizers that includes nutrients such as nitrogen, phosphorous and potassium (N, P, K- nitrogenous, phosphatic and potassic fertilizers). A typical fertilizer industry complex would include ammonia plant (essential for nitrogen fertilizers), acid plants such as phosphoric acid/nitric acid, solvents such as alcohol and different fertilizer units. Thus, the wastewater generated from various plants includes different contaminants such as acids, alcohols, salts and is characterized as having significantly higher values of COD and ammoniacal nitrogen depending upon the source of generation. Some other contaminants such as metals are also present due to the use of rock phosphate. Thus, it is necessary to classify the effluent streams generated at different points as process effluent or effluent from cleaning/ treatment stages. Wastewater treatment is a major problem in such complex fertilizer plant from the environmental pollution point of view. In the manufacture of nitrogenous fertilizers, the nitrates from wastewaters are generally removed using biological treatment; ion exchange can be used for the removal of ammonia and nitrates etc. Leaković et al. [7] reported use of ion exchange-anion exchange resins for nitrogen removal from fertilizer wastewaters. Jorquera et al. [8] suggested process integration of physico-chemical methods and biological methods for effective treatment of effluents from nitrogenous fertilizer plants. Condensate from ammonium nitrate plant contains pollutants such as ammonia, ammonium nitrate and some oxides of nitrogen that are required to be removed prior to discharge $[9,10]$. Wastewater generated from ammonia plant contains ammonia, methanol, trace metals etc. and wastewater treatment involves condensate steam strippers to remove ammonia and methanol followed by ion exchange. The methanol production unit also generates wastewaters containing alcohol and is a major pollution problem.

Application of novel approaches in the existing practice such as newer modified adsorbents or intensified processes not only improve the effluent treatment plant (ETP) operation for better performance at reduced cost, but also provide an incentive for recovering part of the cost of treatment. Thus, it is important to focus on the development of newer 
separation processes and process integration/intensification options that combine or redefine finer aspects of existing physico-chemical methods- mainly adsorption and cavitation. In this regard, we present work on adsorption (newer modified adsorbents) and hydrodynamic cavitation processes (newer cavitating device with vortex flow) for effective removal of COD and ammoniacal nitrogen with specific focus on industrial wastewater treatment in fertilizer Industry.

\section{Adsorption and Hydrodynamic Cavitation}

The existing practices in the fertilizer industry employ well established physico-chemical/biological methods of treatment. It is, however, essential to evolve better techno-economic alternatives that effectively treat different effluents and reduce overall cost of ETP. Two such methods are adsorption and hydrodynamic cavitation. In adsorption, exploring newer types of adsorbents will help in realizing better capacity for removal of various organics and metals. Similarly, newer insight into the application of novel methodologies such as hydrodynamic cavitation is expected to provide better options/alternatives for replacing existing methods and in process intensification.

Adsorption is a well established technique for removal of organics, metals and colours. Thus, in this regard, it can easily serve in reducing the COD of the effluent. Screening of the adsorbent is very important since hundreds of commercial adsorbents of different types are available or can be made. Activated carbons are commonly employed adsorbents that are derived from a variety of sources and are available from a very cheap to expensive materials depending on the type. Adsorption capacity for carbons is typically in the range of 0.25-0.87 kg COD/kg [11] Many chemical industries, in general and fertilizer industry, in particular, have a peculiar problem in reducing ammoniacal nitrogen from wastewaters. Ammoniacal nitrogen $\left(\mathrm{NH}_{3}-\mathrm{N}\right)$ is a measure for the amount of ammonia, a toxic pollutant. Ammoniacal Nitrogen removal can be carried out by biological, physical, chemical or combination of these methods. Available technologies include adsorption, chemical precipitation, membrane filtration, reverse osmosis, ion exchange, air stripping, breakpoint chlorination and biological nitrification and denitrification [12] Conventional methods, however, are not efficient and are cost intensive. Physico-chemical treatment or ion exchange/adsorption is preferred over other methods because of better stability, and reliability. Aguilar et al.[13] investigated the physiochemical removal of AN by coagulation-flocculation using activated silica, powdered activated carbon and precipitated calcium carbonate. They found very low ammonia removal of around 3-17\%, but albuminoid nitrogen (nitrogen in the form of proteins) removal was appreciable (74-89\%) and the addition of coagulant aids reduced the sludge volume to $42 \%$. Ion exchange resins and some cheaper alternatives in the form of natural and waste materials can be used to replace/substitute high cost materials. Recently, Zhao et al. [3] reported ceramic adsorbent for treating high concentration ammonium contaminated wastewaters; Kim et al. [14] suggested amine-grafted adsorbent for recovery of nitrates and phosphates from wastewaters. Newer adsorbents in the form of activated carbons derived from Cassia Fistula were also reported for industrial wastewater treatment [15]. Various researchers have also studied the effectiveness of a variety of low cost materials for ammonia removal such as clay and zeolites, limestone [16-20]; natural and waste materials such as waste paper, refuse cement and concrete [21]. However, not many studies reported work on the treatment of real industrial wastewaters for effective removal of COD and ammoniacal nitrogen using adsorption or newer/ modified adsorbents.

Cavitation can be considered to work similar to advanced oxidation process without employing complex catalyst, high temperature and pressure. Hydrodynamic cavitation in general can be employed for industrial wastewater treatment using simple mechanical devices such as orifice, venturi or complex device such as vortex diode. This is 
schematically shown in Fig. 1. The nature and operating parameters of cavitation set-up enables cavities to get generated, grow and collapse in a predefined manner. In orifice/venturi, cavities get generated when liquid passes through a constriction which in effect increases kinetic energy associated with the liquid at an expense of the local pressure, and when the pressure at the throat or vena-contracta of the constriction falls below the vapor pressure of the liquid, the liquid flashes, generating number of cavities. In vortex diode, vortex flow is employed for generation of cavities. The cavities subsequently collapse when the pressure recovers downstream of the cavitating device, e.g. mechanical constriction [4] The cavity collapse is one of the most important aspect, usually referred as implosion of cavities, resulting in localized extremely high temperatures (up to $5000 \mathrm{~K}$ ) and pressure conditions (up to 1000 atm). Under such extreme conditions water molecules cleave, consequently generating oxidizing agents, e.g. hydroxyl radicals, which can decompose the pollutants partially or fully- similar to the oxidation process. Cavitation technology can be effectively used to treat industrial effluent for removal of COD, ammoniacal nitrogen and/or color. The geometry of the cavitating device and operating parameters such as pressure drop, initial concentration play important role in efficacy of the cavitation/process performance and optimization in terms of these is crucial. Further, cavitation can be employed alone or in combination (process integration) with other processes such as biological treatment process, oxidation, adsorption, ion exchange, coagulation etc.

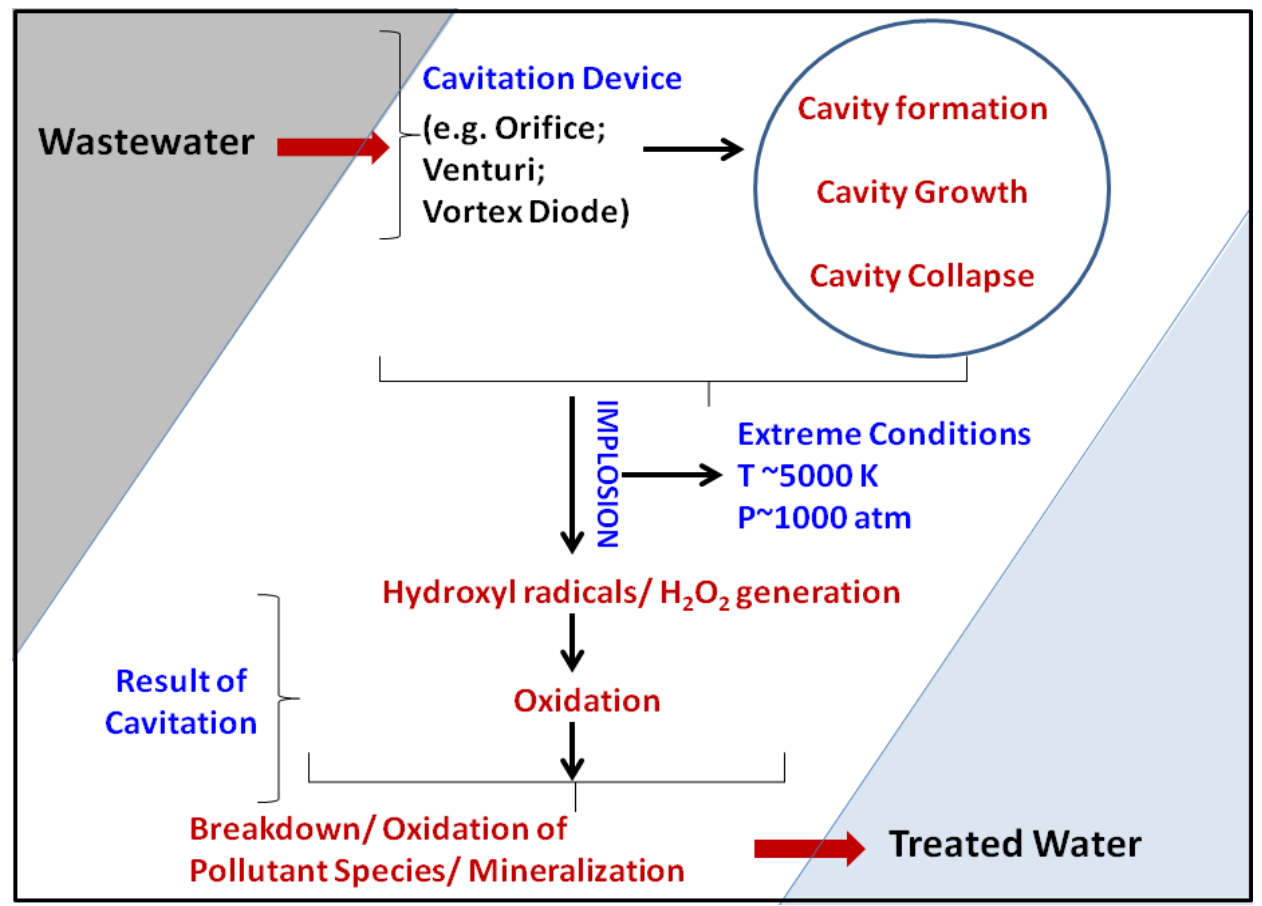

Fig. 1 Schematic representation of Hydrodynamic cavitation method for treatment of wastewater.

Hydrodynamic cavitation is an emerging technology and can be easily employed in wastewater treatment. Cavitation generates strong oxidizing conditions due to production of hydroxyl radicals and also hydrogen peroxide. Although significant work has been reported in the area of sonochemical reactors and its application in wastewater treatment, its implementation in actual industrial practice is still insignificant due to the reasons of the high cost of the treatment and operational difficulties, especially in power utilization. The impact of cavitation processes can be dramatically increased by combining it with other oxidation processes employing catalysts or additives. It has been reported that cavitation coupled with other methods such as coagulation or adsorption can be effective in water treatment and pollutant removal [5,22-26]. Thus, process intensification can work wonders if cavitation and suitable 
other methods are integrated, especially in treating wastewaters containing refractory pollutants and/or having unusually high COD. Mishra and Gogate [23], Sivakumar and Pandit [27] have investigated the use of hydrodynamic cavitation reactors for degradation of Rhodamine B dye solution (5-6 $\mu \mathrm{g} / \mathrm{ml})$.Chakinala et al [28] have reported the applicability of a combination of hydrodynamic cavitation and advanced Fenton process for treatment of industrial effluents. Saharan et al $[29,30]$ have investigated the use of hydrodynamic cavitation reactors for degradation of Acid Red 88 dye solution using venturi and for degradation of orange-G dye (30 to $150 \mu \mathrm{M}$ ) using three different cavitating device viz. a single hole orifice plate, circular venturi and a slit venturi. Hiremath et al [6] recently reported degradation of dyes such as Auramine O using vortex diode.

There are not many reports that evaluate applications of newer cavitating devices for real industrial wastewater treatment, especially in vortex flow. In the present work, we have studied relatively less reported method of hydrodynamic cavitation for industrial wastewater treatment using a newer device-vortex diode and have compared the results with established methods like adsorption.

\section{Materials and methods}

Newer types of commercially available modified carbon based adsorbents- SHIRASAGI X7000H, GS2x, KL, GTSx, TAC, NCC (Japan Envirochemicals Ltd., Japan) were used for effluent treatment using adsorption process. The adsorbents were activated prior to their application. Characterization of the adsorbents was carried out by Scanning electron microscope, SEM (Leo-Leica, Stereoscan 440, Cambridge, UK) attached with Energy dispersive X-ray spectroscopy, EDX (Bruker,Quanrax-200,Berlin,Germany), Pan analytical XRD in the scan range of 2 $\theta$ between 10-80 for all adsorbents in continuous mode using the $\mathrm{Cu} \mathrm{K} \alpha$ radiation (LFF tube $40 \mathrm{kV}, 30 \mathrm{~mA}$ ). Specific surface area was measured by Quantachrome Autosorb Automated Gas Sorption system and calculated by applying Brunaer-EmmettTeller (BET) method. Surface functional groups were determined by Cary 600 Fourier Transform- Infrared, FTIR (Agilent) spectrophotometer having $4 \mathrm{~cm}^{-1}$ resolution using $\mathrm{KBr}$ pellet method in the range $400-4000 \mathrm{~cm}^{-1}$.

The schematic of hydrodynamic cavitation set-up and the pilot plant set-up (capacity $1 \mathrm{~m}^{3} / \mathrm{h}$ ) used in the present study is shown in Fig.2. The setup includes a holding tank of $60 \mathrm{~L}$ capacity, a multistage centrifugal pump of rating $2.2 \mathrm{~kW}$ (2900 RPM), control valves, and vortex diode as a cavitating device for wastewater treatment. The flow rate can be adjusted by adjusting the by-pass valve. Flow transmitter and pressure transmitter were used for the measurements of flow and pressure, respectively and thermocouple for the measurement of temperature. The entire setup was fabricated in SS-316. 


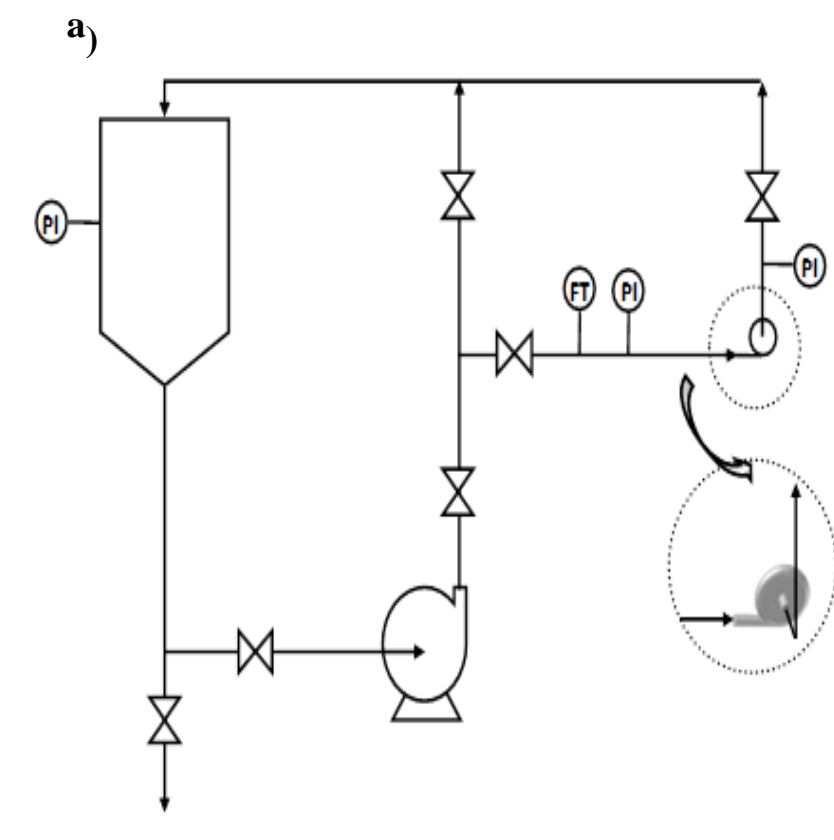

b)

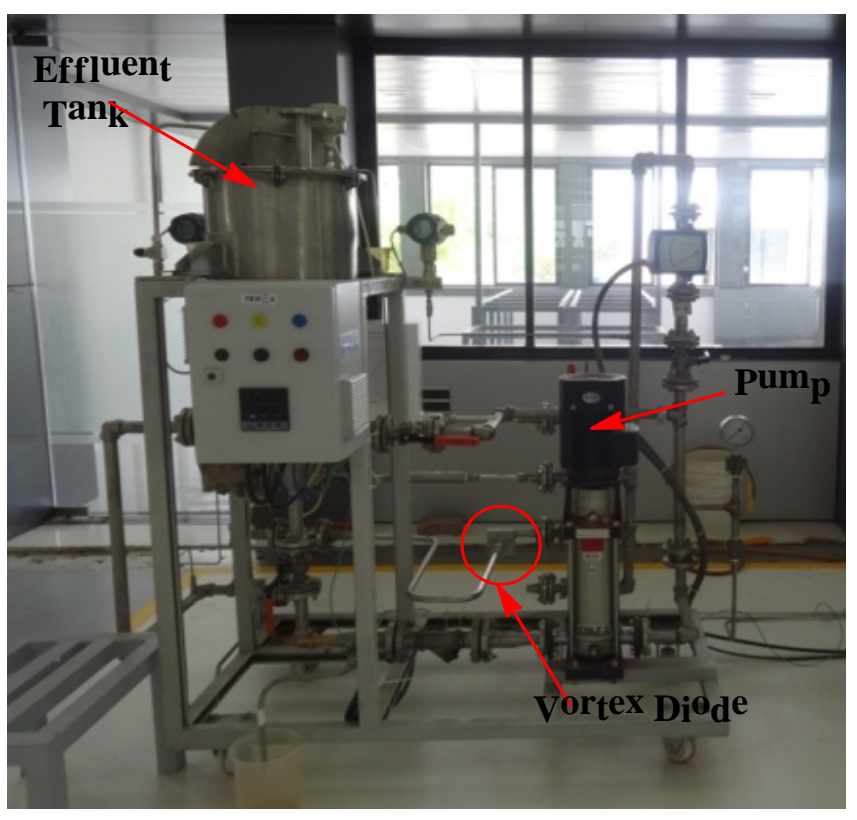

Fig 2. Experimental Set-up for Hydrodynamic Cavitation using Vortex Diode- a) Schematic and b) Pilot plant set up

Industrial wastewater samples were obtained from different locations and plants from a local fertilizer industry and were used for effluent treatment as such without any pre-treatment or addition of chemicals. The effluents were characterized for their initial COD, ammoniacal nitrogen and other physical/chemical parameters. Spectralab MP-5 meter was used for the measurements of $\mathrm{pH}$, TDS and TSS. Measurements of COD and ammoniacal nitrogen were carried out using Spectroquant Pharo 100 spectrophotometer (Merck Limited) where Spectroquant TR 320 was used as digester for digestion of samples for $2 \mathrm{~h}$ at $148{ }^{\circ} \mathrm{C}$. Adsorption equilibria studies were carried out using different adsorbents at ambient conditions $\left(\sim 27^{\circ} \mathrm{C}\right)$. Hydrodynamic cavitation experiments were carried out using vortex diode as a cavitating device and under different pressure drop conditions. The temperature of bulk liquid was maintained by circulating coolant through cooling coils in the holding tank. Cavitation was conducted using aeration for improved degradation. Effects of flow rate and pressure drop were studied by withdrawing the samples at regular intervals of time for the analysis of COD and ammoniacal nitrogen.

\section{Results and Discussion}

The characterization of the industrial effluent samples is given in Table-1. The effluents included those with very high COD, but very low ammoniacal nitrogen and effluent streams with lower COD but with high ammoniacal nitrogen content. Also, the total dissolved solids (TDS) and total suspended solids (TSS) were also different in each of these effluent streams. 
Table 1

Characterization of various effluent streams of Fertilizer Industry

\begin{tabular}{cccl}
\hline $\begin{array}{c}\text { Effluent } \\
\text { Stream }\end{array}$ & $\begin{array}{c}\text { Initial } \\
\text { COD } \\
(\mathrm{ppm})\end{array}$ & $\begin{array}{c}\text { Initial } \\
\mathrm{NH}_{3}-\mathrm{N} \\
(\mathrm{ppm})\end{array}$ & \multicolumn{1}{c}{ Remarks } \\
\hline 1 & 125000 & 2 & $\begin{array}{l}\mathrm{pH} 7-8, \text { Colored, characteristic odor, } \\
\text { low TDS, TSS, presence of alcohols/ } \\
\text { organics }\end{array}$ \\
2 & 946 & 1710 & Very high AN \\
3 & 460 & 86 & pH 10.6, Low TSS, TDS $<2000$ \\
5 & 130 & 1330 & pH 10, High AN, Very low TDS/TSS \\
5 & 44 & 530 & pH 9.6, Low COD \\
5 & 170 & 276 & pH 11, TDS $<2000$ \\
\hline
\end{tabular}

\subsection{Hydrodynamic Cavitation for the treatment of fertilizer industry effluent}

Vortex diodes employ vortex phenomena for its operation. The basic design of a vortex diode consists of cylindrical axial port, a tangential port and a chamber connecting the two ports. The chamber is characterized by its diameter and height, which decide the chamber volume. The flow entering the device through the tangential port sets up a vortex, and establishes a large pressure drop across the device [31]. A generalized form for cavitation number based on pressure drop in vortex diode can be used that defines the cavitation number $\sigma$, as below [32].

$$
\sigma=\frac{\mathrm{p}_{\mathrm{d}}-\mathrm{p}_{\mathrm{v}}}{\mathrm{p}_{\mathrm{u}}-\mathrm{p}_{\mathrm{d}}} \approx \frac{\mathrm{p}_{\mathrm{d}}}{\mathrm{p}_{\mathrm{u}}}
$$

Where $\mathrm{p}_{\mathrm{d}}, \mathrm{p}_{\mathrm{u}}$ and $\mathrm{p}_{\mathrm{v}}$ are downstream, upstream and vapor pressures of the fluid respectively. The approximation holds when $\mathrm{p}_{\mathrm{u}}>>\mathrm{p}_{\mathrm{d}}>>\mathrm{p}_{\mathrm{v}}$. An increase in upstream pressure should decrease $\sigma$ and increase the number of cavitation events. This indicates an increase in the rate of degradation. The definition is different from conventional cavitating devices viz. orifice and venturi, where linear velocity and pressure are related to a dimensionless parameter called as cavitation number $\left(\mathrm{C}_{\mathrm{v}}\right)$. However, since in the vortex diode linear velocity does not exist because of vortex flow, Eq.1 is most appropriate and cavitation numbers obtained by both the definitions should provide similar information. Increase in liquid flow rate with an increase in the diode inlet pressure reduces the cavitation number; number of the cavities generated increases with the decrease in the cavitation number. Ideally, cavities are generated when $C_{v} \leq 1$. However, cavities are also known to get generated at a value of $C_{v}>1$ due to the presence of some dissolved gases and suspended particles which provide additional nuclei for the cavities to form [33]. This is one important aspect in the treatment of real industrial wastewaters that usually have high TSS. After certain value of cavitation number which depends on the specific reactor configuration, the number density of the cavities increases to 
such an extent that cavities start coalescing forming cavity cloud consequently adversely affecting cavitation and degradation due to choked cavitation [34]. Thus, a strategy for effective degradation requires very specific conditions particular to a type of effluent and also requires operation in a specific range between cavitation inception and choked cavitation.

The overall cavitation process can be viewed as a combination of physical and chemical processes. The physical process comprises formation of the cavities, growth of the cavities and subsequent collapse. It would also include a physical breakdown of the pollutant species, if any, due to extreme conditions of temperature and pressure. On the other hand, the chemical part of the overall process involves typical oxidation reactions involving oxidizing species (e.g. $\mathrm{H}_{2} \mathrm{O}_{2}$ and $\mathrm{OH}$ ) and pollutant species. As a result of physical breakdown, formation of smaller molecules that are different from parent species may be expected, while the end product of chemical oxidation is the total mineralization of the pollutant species. The degradation/mineralization therefore results in reduction in COD/ AN or colour, essential for the effluent treatment.

The hydrodynamic cavitation was studied in detail for effluents 1 and 2 specifically for reducing COD (since for other samples, initial COD was not very high), while for other effluent samples 2-6, cavitation was studied for the reduction in ammoniacal nitrogen due to higher values of initial ammoniacal nitrogen. The process parameters were kept constant for all the runs, except for the time of treatment. The most important parameter in hydrodynamic cavitation is the pressure drop across the reactor/cavitating device and is typically optimized for synthetic wastewater streams. Based on the guidelines provided in the literature [1], a pressure drop of $0.5 \mathrm{~kg} / \mathrm{cm}^{2}$ was employed (corresponding to a flow rate of $380 \mathrm{LPH}$ ) for $1^{\text {st }}$ one hour of treatment and $2.0 \mathrm{~kg} / \mathrm{cm}^{2}$ for subsequent treatment (corresponding to a flow rate of $780 \mathrm{LPH}$ ). The results on the reduction of COD in effluent 1 and 2 indicated a very high reduction of 85 and 76\% respectively (Table 2). This is significant in view of very high value of initial COD in effluent 1 and suggests that cavitation alone can be a suitable technology for treating this effluent which doesn't have appreciable ammoniacal nitrogen.

Table 2

Results on Cavitation and Adsorption treatment of Fertilizer effluents

\begin{tabular}{lll|ll|ll}
\hline \multirow{2}{*}{$\begin{array}{l}\text { Effluent } \\
\text { Stream }\end{array}$} & $\begin{array}{l}\text { Initial } \\
\text { COD }\end{array}$ & \multirow{2}{*}{$\begin{array}{l}\text { Initial } \\
\text { AN }\end{array}$} & \multicolumn{4}{|c}{ COD } \\
\cline { 5 - 7 } & $(\mathrm{ppm})$ & Adsorption & Cavitation & Adsorption & Cavitation \\
\hline 1 & 125000 & 2 & - & 85 & NA & NA \\
2 & 946 & 1710 & -- & 76 & -- & 60 \\
3 & 460 & 86 & 80 & $<10$ & 80 & 41 \\
4 & 130 & 1330 & 86 & $<10$ & 30 & 36 \\
5 & 44 & 530 & 65 & $<10$ & 35 & 37 \\
6 & 170 & 276 & 10 & $<10$ & 98 & 87 \\
\hline
\end{tabular}


It is evident that there is substantial variation in the reduction of COD and ammoniacal nitrogen using vortex diode for different effluent samples, even when the COD values were low. Further, the extent of COD reduction was found to be far less for effluents having lower initial COD. This can be attributed mainly to the type of pollutant species believed to be most refractory in nature that remains even at such low initial concentrations. However, it is also possible that the suspended solids contribute to the variation in the performance as the number and quality of the cavities are expected to differ significantly under varying TSS or TDS conditions. It also implies that more severe conditions such as higher pressure drop may be required for improving degradation in such cases. The effect of $\mathrm{pH}$ also needs careful evaluation.

Hydrodynamic cavitation with vortex diode as a cavitating device was highly effective in reducing the ammoniacal nitrogen from the effluent streams. In fact, in most cases the results compare very well with the high removal obtained using adsorption.

\subsection{Effect of number of passes}

The number of passes (Np), can be expressed as -

$$
N_{p}=\frac{\text { Volumetric flow rate } \times \text { Time of operation }}{\text { Volume of effluent in holding tank }}
$$

The extent of degradation increases with increasing number of passes. However, it is essential to optimize the number of passes for economical operation as a higher number of passes directly reflects the higher cost of treatment. Thus, this factor is crucial in determining the cost of operation, less number of passes- lower the cost. It again depends on the nature of the effluent, especially for real industrial effluents for which characteristics such as COD, presence of metals, TDS/TSS vary in most cases, making optimization difficult.

The number of passes, as indicated above, has to be optimized in all the effluent treatments by appropriately selecting process conditions such as cavitating device, pressure drop, process intensification etc. In general, for obtaining high reduction in COD and ammoniacal nitrogen in effluent streams-1 and 2, the number of passes was more than 100, indicating relatively high cost of the cavitation for degradation of the pollutants. This can be attributed to high COD/AN content of these streams. However, for all the other effluent streams, the number of passes was close to 50 for the extent of reduction shown in Table-2, indicating a relatively lower cost of the treatment using hydrodynamic cavitation with vortex diode as a cavitating device. The variation in the performance of the process, however, may have to be attributed to the variation in the nature of pollutants and concentration in different effluent streams and mere values of COD/AN would not provide information in this regard making it difficult to predict the behaviour in terms of degradation or for generalization of the results.

\subsection{Adsorption Process using modified adsorbents for fertilizer industry effluents}

The adsorption process can be successfully employed for reducing COD or for ammoniacal nitrogen using suitable adsorbents. The selection of suitable adsorbent is important as conventional adsorbents have limited or no capacity. Further limitations to employing adsorption include the cost of adsorbent, regeneration/reactivation and rates 
of removal. While adsorption can certainly be useful as a polishing method for lowering COD/ ammoniacal nitrogen below the statutory limits, its use is limited for high initial COD or ammoniacal nitrogen concentrations due to requirement of excessively high adsorbent quantities, making its application techno-economically not feasible. The adsorbents selected in the present study belong to the class of surface modified materials. SHIRASAGI GH2x 4/6 (hereafter referred as GH2x) was a pelletized form of activated carbon reportedly prepared under high temperature steam and impregnated with speciality chemicals. X7000H, a coal based (spherical), KL, a wood based (granular) and remaining GS2x, TAC \& NCC (granular) were reportedly coconut shell derived adsorbents. GS2x 4/6 was reported to exhibit surface modification that is suitable for adsorption of slightly polar compounds. Similarly, TAC (granular activated carbon produced by steam activation) also reported to have modification in the form of impregnation of specialty chemicals/metals to provide characteristic functions. NCC was again similar to TAC but with different metals/ surface modification. KL, a wood based activated carbon, is reportedly produced at high temperatures with zinc chloride and is specifically recommended for removal of industrial chemicals. X7000 is reportedly a specialty carbon made from bituminous coal and is believed to be suitable for industrial wastewater treatment. The measured BET

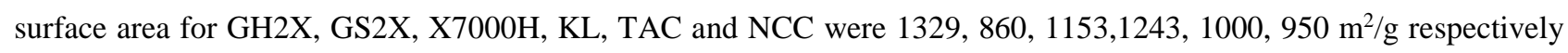
and the details of characterization has been reported earlier [35]. The screening of the adsorbent was carried out using batch equilibrium studies. Adsorbent loading of $2.5 \%$ was used to evaluate effectiveness in the removal of COD/ammoniacal nitrogen.

The results on the modified adsorbents for the treatment of various fertilizer industry effluents are shown in Fig. 3 to 6 for low COD effluent streams, 3-6. It is evident that there was significant variation in the performance of various adsorbents in spite of the fact that all of these adsorbents are modified activated carbons. Further the removal capacities were drastically different for different effluent streams. All these effluent streams were basic with $\mathrm{pH} \sim 10$ and vary in terms of initial COD or ammoniacal nitrogen content. For the effluent stream-3, the initial COD was 460 ppm while AN value was 86 ppm. It can be seen that most of the adsorbents of this work show more or less satisfactory removal of COD and AN for this particular stream and maximum COD reduction of $\sim 80 \%$ was obtained using GS2x while $\sim 80 \%$ reduction in AN was obtained using TAC adsorbent. For most other adsorbents, the removal was $\sim 60 \%$ for both COD and AN.

Effluent sample-4 had a very high AN of $\sim 1330 \mathrm{ppm}$ and low COD of $130 \mathrm{ppm}$. Thus, this stream requires treatment only for the removal of ammoniacal nitrogen. However, as against effluent stream-3, all the adsorbents were less effective for the removal of $\mathrm{AN}$ and a maximum reduction of only $\sim 30 \%$ could be obtained using TAC as an adsorbent. Thus, adsorption here appears to be a less satisfactory method for removal of ammoniacal nitrogen from such effluents.

Effluent streams 5 and 6, both had reasonably high ammoniacal nitrogen (530 \& 276 ppm respectively) and low COD. Again, similar to effluent stream - 4, here too, no adsorbent was found suitable for removal of AN from stream-5 and a maximum reduction of $\sim 35 \%$ could be obtained using TAC adsorbent. However, for effluent stream-6, near complete AN removal ( 98\%) was obtained using $\mathrm{X7000H}$ adsorbent while TAC gave $\sim 50 \%$ reduction. Interestingly, here, even the hydrodynamic cavitation using vortex diode yields $87 \%$ removal of AN similar to adsorption. 
$\mathrm{X} 7000 \mathrm{H}$ is a coal based while TAC \& NCC are coconut shell derived adsorbents. TAC has indicated the presence of metals such as copper and Chromium on its surface while, $\mathrm{X} 7000 \mathrm{H}$ indicated presence of potassium, which is likely to expand interlayers of adjacent hexagonal network planes consisting of $\mathrm{C}$ atoms, enhance pore formation and as a consequence give better adsorption. Presence of $\mathrm{Ni}$ in $\mathrm{X7000H}$ is also expected to enhance adsorption. GH2x also has a much higher surface area of $\sim 1329 \mathrm{~m}^{2} / \mathrm{g}$ and indicated presence of elements like Al and Si [36]. The better adsorption behaviour for $\mathrm{X} 7000 \mathrm{H}$, TAC and GH2x can be attributed to these specific modifications as compared to the other adsorbents.

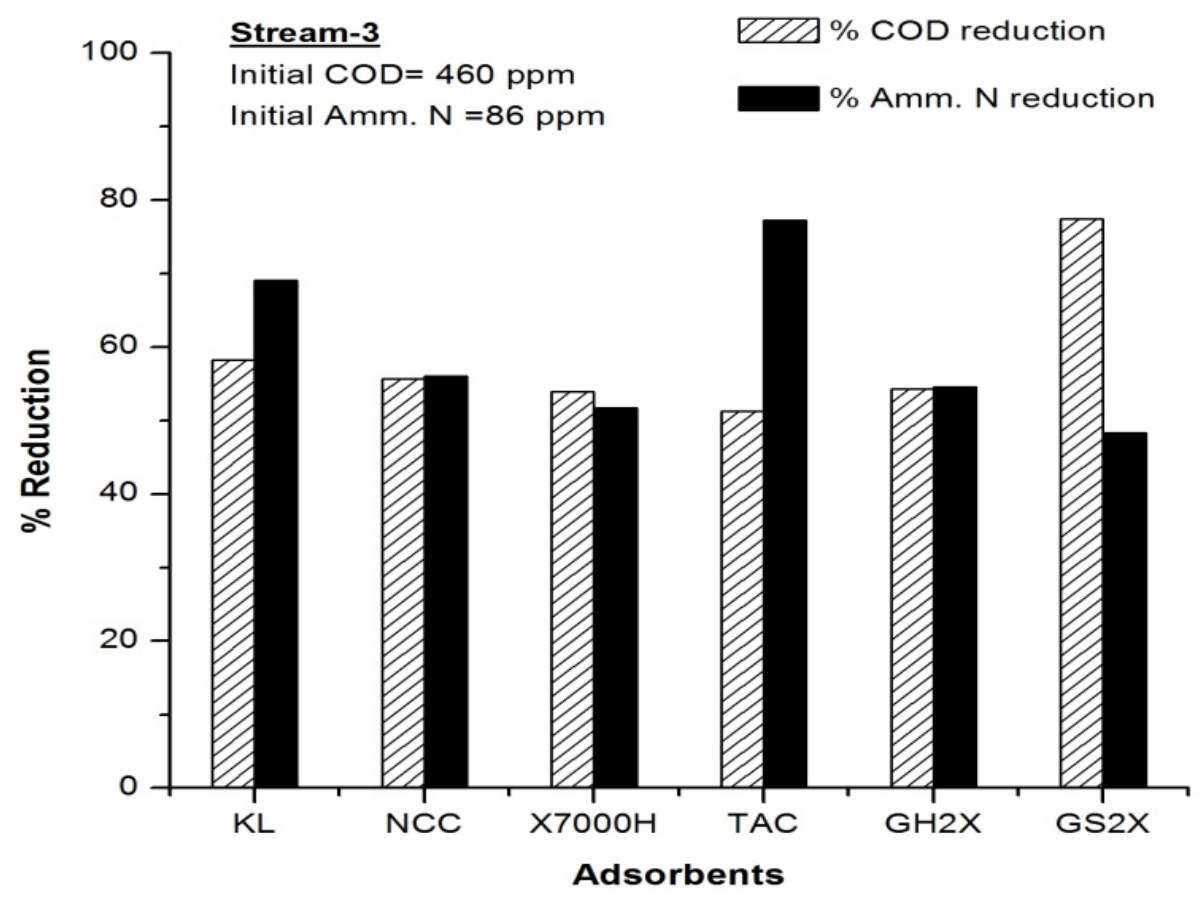

Fig. 3. Effluent-3: COD/AN reduction using adsorption with modified adsorbents 


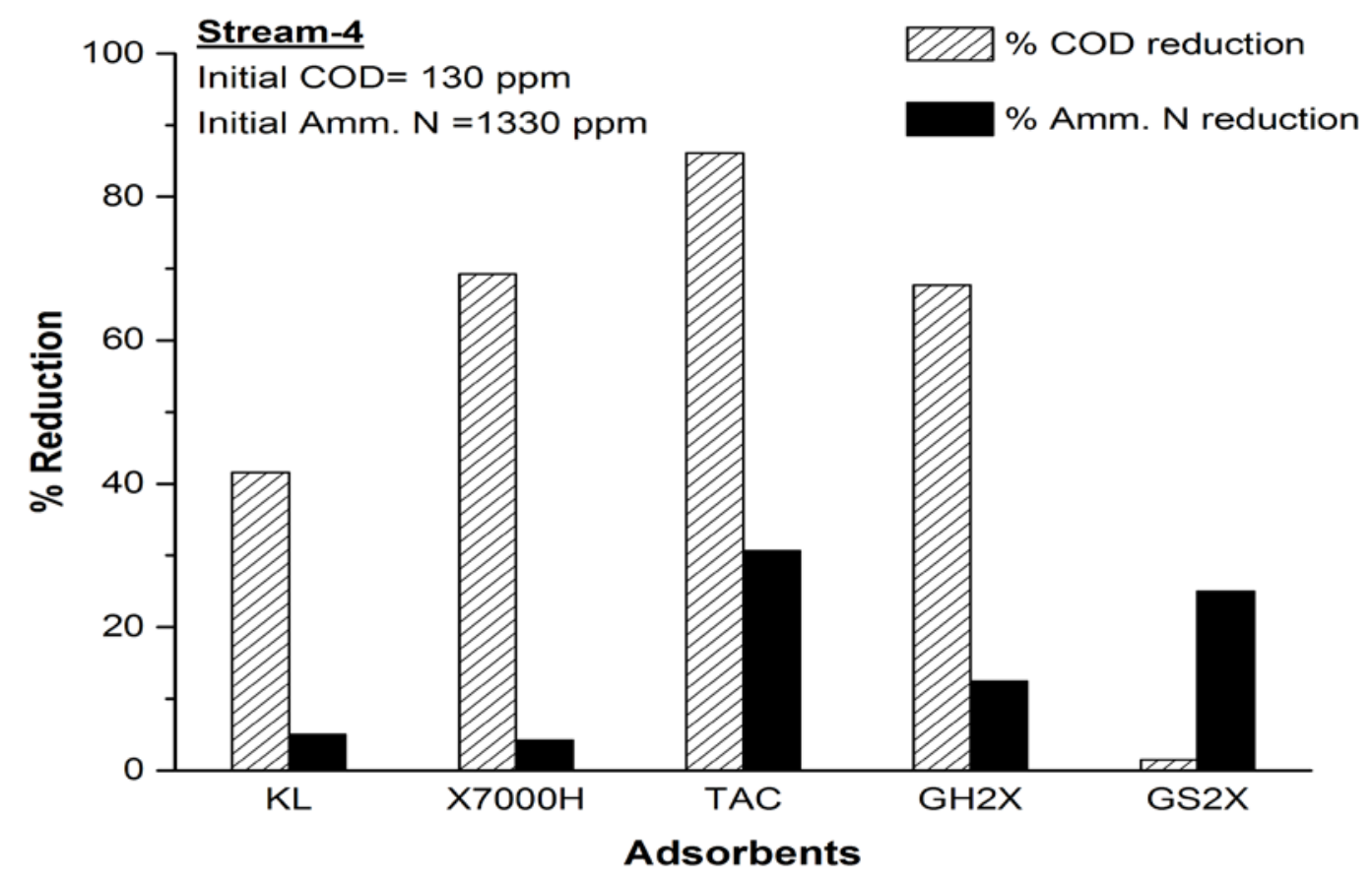

Fig. 4. Effluent-4: COD/AN reduction using adsorption with modified adsorbents

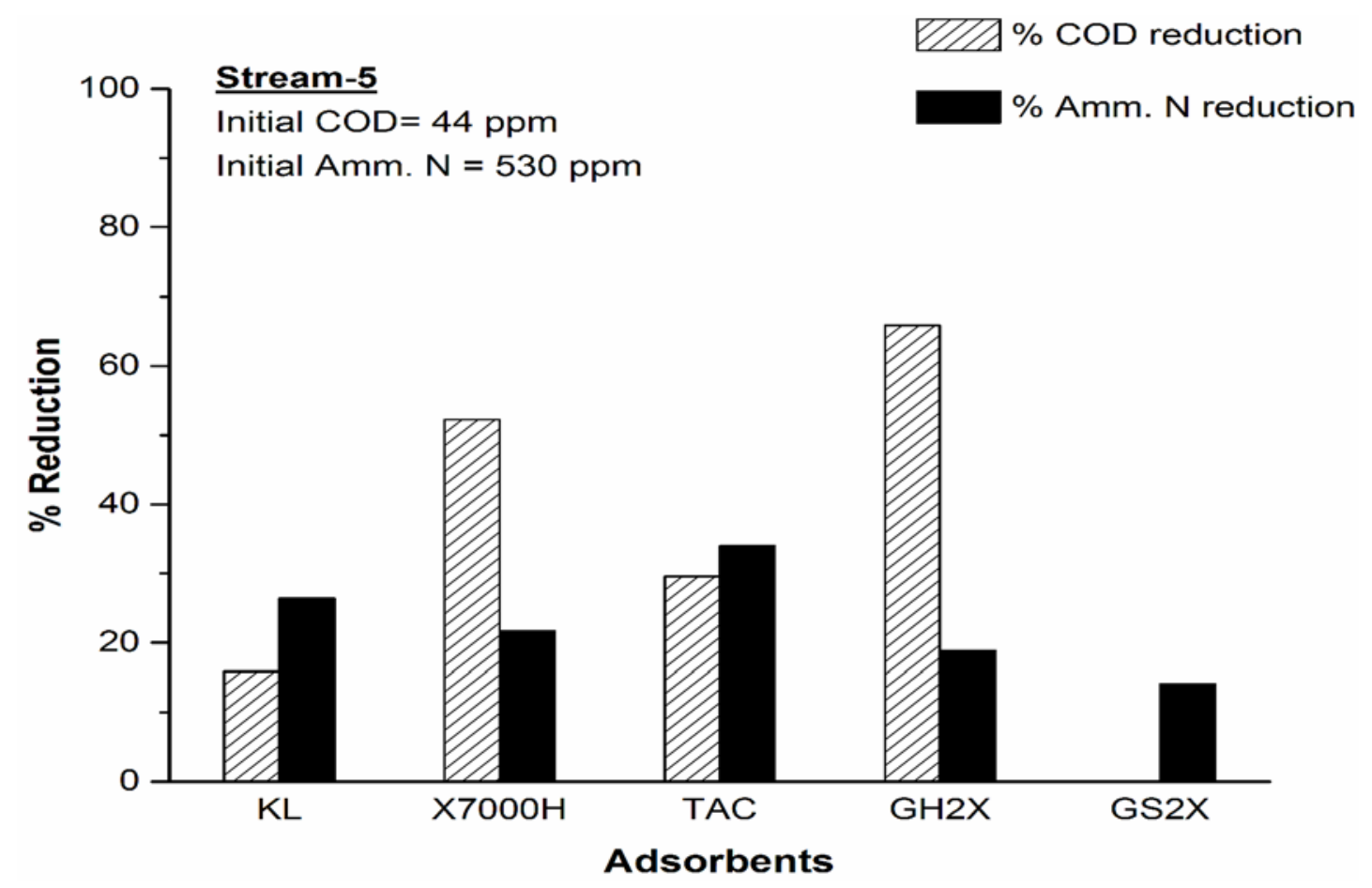

Fig. 5. Effluent-5: COD/AN reduction using adsorption with modified adsorbents 


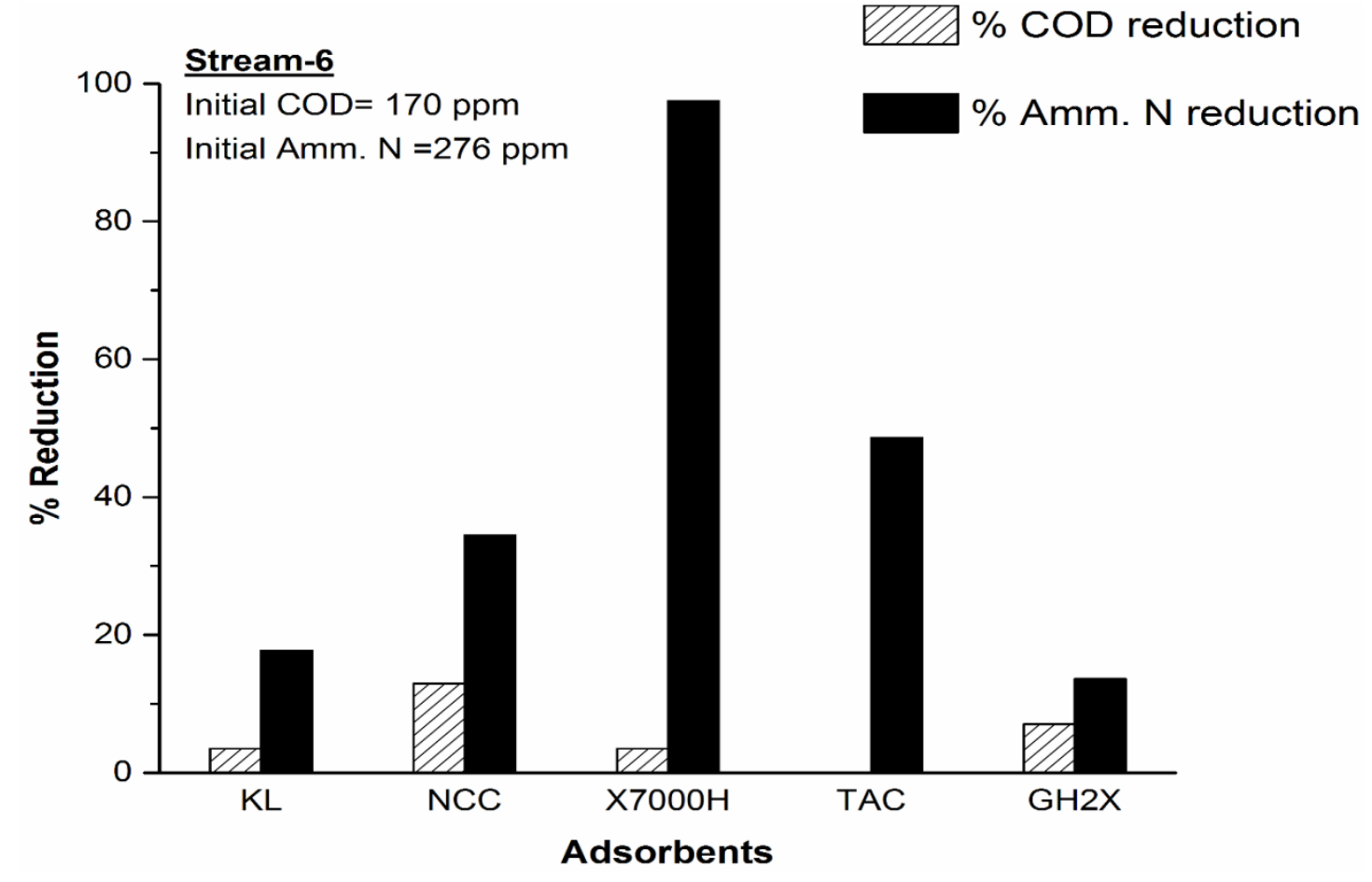

Fig. 6. Effluent-6: COD/AN reduction using adsorption with modified adsorbents

\subsection{Comparison of adsorption and hydrodynamic cavitation using vortex diode}

The results on cavitation and adsorption can be summarized for comparison in Table-2. Though it is not possible to directly correlate the cost of the two processes at this point, it can be seen that cavitation is an effective technology in treating effluents for reducing COD and AN simultaneously. Especially for reducing ammoniacal nitrogen, cavitation appears to be more effective as compared to adsorption.

A close examination of the results on adsorption and cavitation revealed following very interesting observations:

1. Hydrodynamic cavitation using vortex diode appears to be an effective method for the treatment of industrial wastewaters.

2. Being a destructive method and requiring no regeneration/ reagents/ catalyst, hydrodynamic cavitation may be advantageous over other conventional treatment methods.

3. Hydrodynamic cavitation using vortex diode requires substantially less space as compared to methods such as coagulation/clarification, biological treatment etc.

4. A very high removal of COD and AN can be obtained using adsorption and hydrodynamic cavitation-vortex diode.

5. The energy requirements for the treatment of various effluents vary substantially depending on the nature of effluent, presence of organics/TSS/TDS and refractory pollutants that necessitates careful optimization in terms of processing parameters such as pressure drop, number of passes etc.

6. Where, hydrodynamic cavitation, alone, is not satisfactory for a complete treatment, it can be easily combined practically with all other methods of treatment- e.g. coagulation, adsorption, biological treatment etc.

7. The removal of COD and AN differs significantly for different adsorbents and for different streams indicating the selection of suitable adsorbent as a most crucial step in this regard. 
8. Adsorption, though effective for removal of both COD and AN, can be best implemented as a polishing step for techno-economic feasibility of overall ETP operation.

\section{Conclusions}

The results of the present study clearly highlight the usefulness and limitations in employing established effluent treatment methods such as adsorption and relatively new method of hydrodynamic cavitation using vortex diode. Hydrodynamic cavitation using vortex diode was found to be an effective newer technology for the treatment of various effluent streams from fertilizer industry, especially for a large reduction of COD and ammoniacal nitrogen. It can also be effectively integrated with other conventional methods of treatment for overall cost optimization in ETP operation. Adsorption using modified adsorbents was effective for high COD and ammoniacal reduction for effluent streams, especially for low COD streams. However, not all adsorbents are suitable and finding most suitable adsorbent for the given stream is important. The findings, especially with respect to employing hydrodynamic cavitation using vortex diode, are expected to be useful not just for fertilizer industry wastewater streams, but also for chemical industry effluents, in general.

\section{Acknowledgements}

The authors wish to acknowledge financial support from IndusMagic (CSC0123) and SETCA (CSC0113) of Council of Scientific \& Industrial Research(CSIR), India for the research work.

\section{List of symbols}

$\begin{array}{ll}\text { AN } & \text { Ammoniacal nitrogen } \\ \text { BET } & \text { Brunaer-Emmett-Teller } \\ \text { COD } & \text { Chemical Oxygen Demand } \\ \text { EDX } & \text { Energy dispersive X-ray spectroscopy } \\ \text { ETP } & \text { Effluent treatment plant } \\ \text { FTIR } & \text { Fourier Transform- Infrared } \\ \text { LPH } & \text { Liters per hour } \\ \text { RPM } & \text { Revolutions per minute } \\ \text { SEM } & \text { Scanning electron microscope } \\ \text { TDS } & \text { Total dissolved solids } \\ \text { TSS } & \text { Total suspended solids } \\ C_{v} \sigma & \text { Cavitation number } \\ N_{p} & \text { number of passes } \\ p_{d} & \text { downstream pressure of the fluid }\end{array}$




\section{References}

[1] V. V. Ranade, V.M. Bhandari, Industrial Wastewater Treatment, Recycling and Reuse, Elsevier, 2014. doi:10.1016/B978-0-08-099968-5.09986-4.

[2] Manual on sewerage and sewage treatment, n.d. http://www.indiaenvironmentportal.org.in/files/file/Manual on sewerage and sewage treatment.pdf (accessed March 28, 2016).

[3] Y. Zhao, Y. Yang, S. Yang, Q. Wang, C. Feng, Z. Zhang, Adsorption of high ammonium nitrogen from wastewater using a novel ceramic adsorbent and the evaluation of the ammonium-adsorbed-ceramic as fertilizer., J. Colloid Interface Sci. 393 (2013) 264-70. doi:10.1016/j.jcis.2012.10.028.

[4] P.R. Gogate, A.B. Pandit, A review of imperative technologies for wastewater treatment I: oxidation technologies at ambient conditions, Adv. Environ. Res. 8 (2004) 501-551. doi:10.1016/S1093-0191(03)000327.

[5] V.V. Ranade, A.A. Kulkarni, V.M. Bhandari, Vortex diodes as effluent treatment devices, PCT/IN2012/000676, 2013. http://www.google.com/patents/WO2013054362A3?cl=en.

[6] R.S. Hiremath, V.M. Bhandari, V. V. Ranade, Effluent Treatment Using Hydrodynamic Cavitation: Vortex Diode As a Cavitating Device, in: AIChE 2013 Annu. Meet., 2013.

[7] S. Leaković, I. Mijatović, Š. Cerjan-Stefanović, E. Hodžić, Nitrogen removal from fertilizer wastewater by ion exchange, Water Res. 34 (2000) 185-190. doi:10.1016/S0043-1354(99)00122-0.

[8] O. Jorquera, R. Kalid, A. Kiperstok, E. Braga, E.A. Sales, Effluent stream treatment in a nitrogenous fertilizer factory: An exergy analysis for process integration, Process Saf. Environ. Prot. 92 (2014) 862-868. doi:10.1016/j.psep.2013.07.003.

[9] Egyptian Environmental Affairs Agency (EEAA) Egyptian Pollution Abatement Project (EPAP), 2002. http://industry.eeaa.gov.eg/publications/Fertilizers IM- 2003.pdf (accessed March 28, 2016).

[10] Indian Standard: Guide For Treatment And Disposal of Effluents Of Fertilizer Industry, Bur. INDIAN Stand. NEW DELHI. (2009). https://law.resource.org/pub/in/bis/S02/is.9841.1981.html (accessed March 28, 2016).

[11] P. Guyer, An Introduction to Advanced Wastewater Treatment, Eng. Edge, LLC PDH Prof. Train. (2011) 1-6. http://www.cedengineering.com/courseoutline.asp (accessed April 12, 2015).

[12] G. Tchobanoglous, F.L. Burton, Metcalf, Eddy, Wastwater Engineering: Treatment, Disposal,Reuse, 3rd ed., McGraw-Hill Int., New York, 1991.

[13] M. Aguilar, Nutrient removal and sludge production in the coagulation-flocculation process, Water Res. 36 (2002) 2910-2919. doi:10.1016/S0043-1354(01)00508-5.

[14] J. Kim, M.-J. Hwang, S.-J. Lee, W. Noh, J.M. Kwon, J.S. Choi, et al., Efficient recovery of nitrate and phosphate from wastewater by an amine-grafted adsorbent for cyanobacterial biomass production., Bioresour. Technol. 205 (2016) 269-73. doi:10.1016/j.biortech.2016.01.055.

[15] L.G. Sorokhaibam, V.M. Bhandari, M.S. Salvi, S. Jain, S.D. Hadawale, V. V. Ranade, Development of Newer Adsorbents: Activated Carbons Derived from Carbonized Cassia fistula, Ind. Eng. Chem. Res. (2015) acs.iecr.5b02945. doi:10.1021/acs.iecr.5b02945.

[16] H.A. Aziz, M.N. Adlan, M.S.M. Zahari, S. Alias, Removal of ammoniacal nitrogen (N-NH3) from municipal solid waste leachate by using activated carbon and limestone., Waste Manag. Res. 22 (2004) 371-5. http://www.ncbi.nlm.nih.gov/pubmed/15560441 (accessed April 12, 2015).

[17] A. Demir, A. Gunay, E. Debik, Ammonium removal from aqueous solution by ion-exchange using packed bed natural zeolite, Water SA. 28 (2002) 329-336. doi:10.4314/wsa.v28i3.4903.

[18] M. Sarioglu, Removal of ammonium from municipal wastewater using natural Turkish (Dogantepe) zeolite, Sep. Purif. Technol. 41 (2005) 1-11. doi:10.1016/j.seppur.2004.03.008.

[19] M.S. Çelik, B. Özdemir, M. Turan, I. Koyuncu, G. Atesok, H.. Sarikaya, Removal of ammonia by natural clay minerals using fixed and fluidised bed column reactors, Water Sci. Technol. Water Supply. 1 (2001) 81-88.

[20] M. Rozic, Ammoniacal nitrogen removal from water by treatment with clays and zeolites, Water Res. 34 (2000) 3675-3681. doi:10.1016/S0043-1354(00)00113-5. 
[21] S. Ahsan, Use of some natural and waste materials for waste water treatment, Water Res. 35 (2001) 3738-3742. doi:10.1016/S0043-1354(01)00047-1.

[22] X. Wang, J. Jia, Y. Wang, Degradation of C.I. Reactive Red 2 through photocatalysis coupled with water jet cavitation., J. Hazard. Mater. 185 (2011) 315-21. doi:10.1016/j.jhazmat.2010.09.036.

[23] K.P. Mishra, P.R. Gogate, Intensification of degradation of Rhodamine B using hydrodynamic cavitation in the presence of additives, Sep. Purif. Technol. 75 (2010) 385-391. doi:10.1016/j.seppur.2010.09.008.

[24] A.G. Chakinala, P.R. Gogate, A.E. Burgess, D.H. Bremner, Industrial wastewater treatment using hydrodynamic cavitation and heterogeneous advanced Fenton processing, Chem. Eng. J. 152 (2009) 498-502. doi:10.1016/j.cej.2009.05.018.

[25] V.V. Ranade, A. Pandit, A. Anil, S. Sawant, D. Ilangovan, R. Madhan, et al., Apparatus for filtration and disinfection of seawater/ship's ballast water and a method of same, US20080017591 A1, 2008. http://www.google.co.in/patents/US20080017591.

[26] V. V. Ranade, V.M. Bhandari, Industrial Wastewater Treatment, Recycling and Reuse: An Overview, in: Ind. Wastewater Treat. Recycl. Reuse, Elsevier, 2014: pp. 1-80. doi:10.1016/B978-0-08-099968-5.00001-5.

[27] M. Sivakumar, A.B. Pandit, Wastewater treatment: a novel energy efficient hydrodynamic cavitational technique., Ultrason. Sonochem. 9 (2002) 123-31. http://www.ncbi.nlm.nih.gov/pubmed/12154685 (accessed April 12, 2015).

[28] A.G. Chakinala, P.R. Gogate, A.E. Burgess, D.H. Bremner, Treatment of industrial wastewater effluents using hydrodynamic cavitation and the advanced Fenton process., Ultrason. Sonochem. 15 (2008) 49-54. doi:10.1016/j.ultsonch.2007.01.003.

[29] V.K. Saharan, A.B. Pandit, P.S. Satish Kumar, S. Anandan, Hydrodynamic Cavitation as an Advanced Oxidation Technique for the Degradation of Acid Red 88 Dye, Ind. Eng. Chem. Res. 51 (2012) 1981-1989. doi:10.1021/ie200249k.

[30] V.K. Saharan, M.A. Rizwani, A.A. Malani, A.B. Pandit, Effect of geometry of hydrodynamically cavitating device on degradation of orange-G., Ultrason. Sonochem. 20 (2013) 345-53. doi:10.1016/j.ultsonch.2012.08.011.

[31] A.A. Kulkarni, V. V. Ranade, R. Rajeev, S.B. Koganti, Pressure drop across vortex diodes: Experiments and design guidelines, Chem. Eng. Sci. 64 (2009) 1285-1292. doi:10.1016/j.ces.2008.10.060.

[32] K.S. Suslick, M.M. Mdleleni, J.T. Ries, Chemistry Induced by Hydrodynamic Cavitation, J. Am. Chem. Soc. 119 (1997) 9303-9304. doi:10.1021/ja972171i.

[33] Y.T. Shah, A.B. Pandit, V.S. Moholkar, Cavitation Reaction Engineering, Springer US, 1999. doi:10.1007/9781-4615-4787-7.

[34] S.S. Sawant, A.C. Anil, V. Krishnamurthy, C. Gaonkar, J. Kolwalkar, L. Khandeparker, et al., Effect of hydrodynamic cavitation on zooplankton: A tool for disinfection, Biochem. Eng. J. 42 (2008) 320-328. doi:10.1016/j.bej.2008.08.001.

[35] A. Pund, L.G. Sorokhaibam, V.M. Bhandari, V.. Patil, V.V. Ranade, Newer adsorbents and cavitation intensified process for dye wastewater treatment, in: Int. Conf. Environ. Ecol., Kolkatta, 2015.

[36] S. V. Patil, L.G. Sorokhaibam, V.M. Bhandari, D.J. Killedar, V. V. Ranade, Investigating role of sulphur specific carbon adsorbents in deep desulphurization, J. Environ. Chem. Eng. 2 (2014) 1495-1505. 